\title{
From study to work: Methodological challenges of a graduate destination survey in the Western Cape, South Africa
}

\author{
Jacques L. du Toit ${ }^{\mathrm{a} *}$, Andre Kraak ${ }^{\mathrm{b}}$, Judy Favish $^{\mathrm{c}}$, and Lizelle Fletcher ${ }^{\mathrm{d}}$ \\ ${ }^{a}$ Department of Town and Regional Planning, University of Pretoria, Private Bag X20, Hatfield, \\ Pretoria, 0028, South Africa; ${ }^{b}$ Research Associate, School of Education, University of Cape Town, \\ Private Bag X3, Rondebosch, Cape Town, 7701, South Africa; ${ }^{c}$ Department of Institutional Planning and \\ Development, University of Cape Town, Private Bag X3, Rondebosch, Cape Town, 7701, South Africa; \\ ${ }^{d}$ Department of Statistics, University of Pretoria, Private Bag X20, Hatfield, Pretoria, 0028, South Africa \\ *Corresponding author. Email: jacques.dutoit@up.ac.za
}

Jacques du Toit was previously a Senior Researcher in the Human Resources Development Research Programme at the South African Human Sciences Research Council. His areas of research include higher education, research methodology, planning methods and techniques, and environment-behaviour studies.

Andre Kraak was previously Executive Director of the Human Resources Development Research Programme at the South African Human Sciences Research Council. He is currently a research consultant on education and training. His research interests span further and higher education, skills development, and science and technology policy studies.

Judy Favish is Director of the Institutional Planning Department at the University of Cape Town. She serves as the co-chair of a joint task team consisting of representatives from the four universities in the Western Cape and the Western Cape Government. In this capacity she chaired the Reference Group that was established to oversee the Western Cape Graduate Destination Survey.

Lizelle Fletcher manages the Internal Statistical Consultation Service at the University of Pretoria rendering support to academic staff and postgraduate students. She has assisted researchers across various disciplines in most of the University's faculties.

Current literature proposes several strategies for improving response rates to student evaluation surveys. Graduate destination surveys pose the difficulty of tracing graduates years later when their contact details may have changed. This article discusses the methodology of one such a survey to maximise response rates. Compiling a sample frame with reliable contact details was foremost important, but may require using additional sources of information other than university records. In hindsight, graduates should have been contacted prior to introduce the survey and mention its importance, while email and postal reminders appeared to have a limited effect on non-respondents. Due to varying 
response rates between participating universities, online responses were augmented with a call centre administering the survey telephonically to nonrespondents. Although overall differences between online and telephonic responses appeared to be small, certain question items may need to be treated with caution when conducting telephonic surveys. The article concludes by highlighting some of the benefits of the Western Cape graduate destination survey.

Keywords: Western Cape; graduate destination survey; call centre; response rates

\section{Introduction}

The term 'graduate destination surveys', also known as 'alumni' or 'tracer' surveys, probably owes its existence to the Australian graduate destination survey that has been administered since 1972 (Alderman, Towers and Bannah 2012, 265). South Africa is currently showing more interest in graduate destination surveys, in particular those assessing the notion of different 'pathways' from study to work. The latter follows perceived levels of graduate unemployment in many countries affected by the 2008 and subsequent global financial crises, but also debates in South Africa as to whether graduate unemployment levels actually warrant concern (Van der Berg and Van Broekhuizen 2012). While the literature on regional, national or cross-national graduate destination surveys is scarce, with some exceptions in Australia, Africa and Europe (e.g., see Teichler [2002], Mugabushaka, Teichler and Schomburg [2003]), Schomburg and Teichler [2006], and Alderman, Towers and Bannah [2012, 266-267]), the methodological literature on graduate destination surveys is even more so. Yet, two important challenges facing graduate destination surveys include compiling a sample frame with reliable contact details and administering a survey mode to yield maximum response rates (e.g., see Porter [2004a] about the advantages and disadvantages of online versus paper surveys). 
Before the advent of online surveys, Smith and Bers (1987) tested Dillman's Total Design Method for postal surveys, and found that an integrated approach combining personal appeals with well-organised follow-ups (reminders) yielded maximum response rates. With the advent of online surveys, Porter (2004b) synthesised the literature on maximising response rates and argued that online surveys may yield response rates equal to or even greater than postal surveys depending on the population and design of the online survey. Other factors for increasing response rates included using multiple contacts, shortening questionnaires, offering incentives, emphasising importance and stating confidentiality (Porter 2004b, 16-17). The more recent literature focuses largely on the issue of online versus postal response rates (Dommeyer et al. 2004; Ardalan et al. 2007; Nulty, 2008). While Nulty (2008, 303-306) discusses several standard procedures for increasing online responses, Nair, Adams and Mertova (2008) highlight the benefit of call centres first introducing surveys to students or graduates. Similarly, Bennett and Nair (2010) argue the importance of universities using various communication mediums to inform students before, during and after a survey.

The literature above focuses almost exclusively on 'student evaluation surveys' or 'student feedback surveys' (Alderman, Towers and Bannah 2012, 263 \& 265-267) (also known in South Africa as 'exit surveys'), that are usually conducted shortly before, during or immediately after graduation when universities have relatively up-todate contact details for students. Graduate destination surveys are more difficult in that many graduates acquire new contact details as soon as they leave university, let alone a number of years after graduating. Graduates change residence, acquire work email addresses or sign new mobile contracts upon starting to earn salaries, etc. Regional or national graduate destination surveys are even more difficult in terms of standardising contact details across different universities and designing questionnaires for diverse 
student populations. Moreover, graduate destination survey questionnaires are complex to start with, focussing not only on evaluation of university teaching and qualifications, but also on different pathways from study to work, further study, future aspirations, etc. The complexity of graduate destination survey questionnaires in turn makes implementing an optimal survey mode even more important. Yet, literature on these types of methodological challenges around graduate destination surveys is lacking. This article therefore discusses the methodology of one such a survey, namely the Western Cape graduate destination survey. The Western Cape, one of South Africa's nine provinces, is geographically and socio-economically fairly distinct with its own regional dynamics. Following a Graduate Attributes Symposium in 2011, the survey was commissioned during 2012 by the Cape Higher Education Consortium (CHEC), which represents the four universities in the province, including the Cape Peninsula University of Technology (CPUT), Stellenbosch University (SU), the University of Cape Town (UCT) and the University of the Western Cape (UWC) - all located around Cape Town, South Africa's second largest city. The Western Cape survey traced the entire cohort of graduates who received a certificate, diploma or degree during 2010 from one of the four universities - a total of 24710 graduates. The survey, conducted between September and November 2012, about two years after graduates finished their studies, focused mainly on graduates' experience of university, finding employment and studying further (CHEC 2013).

The Western Cape graduate destination survey is the first attempt by a consortium of universities in South Africa to trace an entire cohort of graduates from a particular region. Graduate destination surveys are otherwise underdeveloped in South Africa and mostly limited to exit surveys, with only certain universities conducting their own exit surveys around graduation ceremonies (CHEC 2013, 7). Yet, exit surveys are 
too early to assess pathways from study to work (hence, actual levels of graduate employment), and cannot provide information on graduates' employment experiences in relation to their qualifications. Only two national surveys of graduates have been conducted in the past decade in South Africa, one by the Development Policy Research Unit at the University of Cape Town, which involved an econometric analysis of Statistics South Africa's Labour Force Survey data between 1995 and 2005 (DPRU 2006), and the other by the South African Human Sciences Research Council, which involved a tracer of both 'leavers' ('drop-outs') and graduates from seven selected universities (Letseka et al. 2010). Yet, these have become dated while the analysis was at a national level only. Some commercial surveys target South African graduates, but mostly to inform prospective employers rather than institutional research and planning offices (e.g., see Magnet [2008] and Universum [2013]).

The discussion of the methodology of the Western Cape survey focuses on two important challenges facing graduate destination surveys; compiling a sample frame with reliable contact details and administering a survey mode to yield maximum response rates. The survey was initially administered online only, but, following concerns about response rates, was later also administered telephonically with a call centre contacting random samples of non-responding graduates to conduct the questionnaire telephonically. Because of the effect the two different survey modes may have had on the validity of responses, the difference in responses between online and telephonic surveys is discussed in more detail.

\section{Compiling the sample frame}

Compiling the sample frame came down to obtaining the best possible data on graduate contact details in the most standardised format possible from the four Western Cape universities. A reference group, consisting of stakeholders from CHEC, the four 
universities, and the Western Cape Provincial Government (who also had an interest in the outcome of the survey, especially with regard to employment), was set up to oversee the project. The reference group included a 'data' committee comprising representatives from the Institutional Planning and Research offices at each university. The data committee sourced graduate details from its respective Higher Education and Management Information Systems (HEMISs) and provided these to a research team comprising two independent consultants and a private call centre responsible for managing and executing the survey. Because the data contained personal details of graduates, both consultants and the call centre signed confidentiality agreements that no details would be disclosed other than for surveying gradates as part of the Western Cape graduate destination survey.

The research team had to meticulously standardise the different databases from the four universities and merge them into a single database to comprise the sample frame. Table 1 shows the sample frame totalling 24710 graduates, disaggregated by four key descriptors, including (1) race, (2) gender, (3) university, and (4) qualification type - all of which were pertinent to a survey of this kind that had to depict the South African social landscape.

Although the sample frame was complete in terms of the four key descriptors (i.e., each graduate was accounted for in terms of his/her race, gender, university and qualification type), contact details, which included emails, mobile- and home numbers, and postal addresses, were far less complete, while the quality of the data also varied considerably between universities. The gap between 2010 and the time of conducting the survey in 2012 posed further difficulties as many graduates would have since acquired new contact details for reasons mentioned earlier. Moreover, none of the alumni offices was able to provide contact details over and above what the data 
Table 1. Total number of graduates by race, gender, university and qualification type (sample frame).

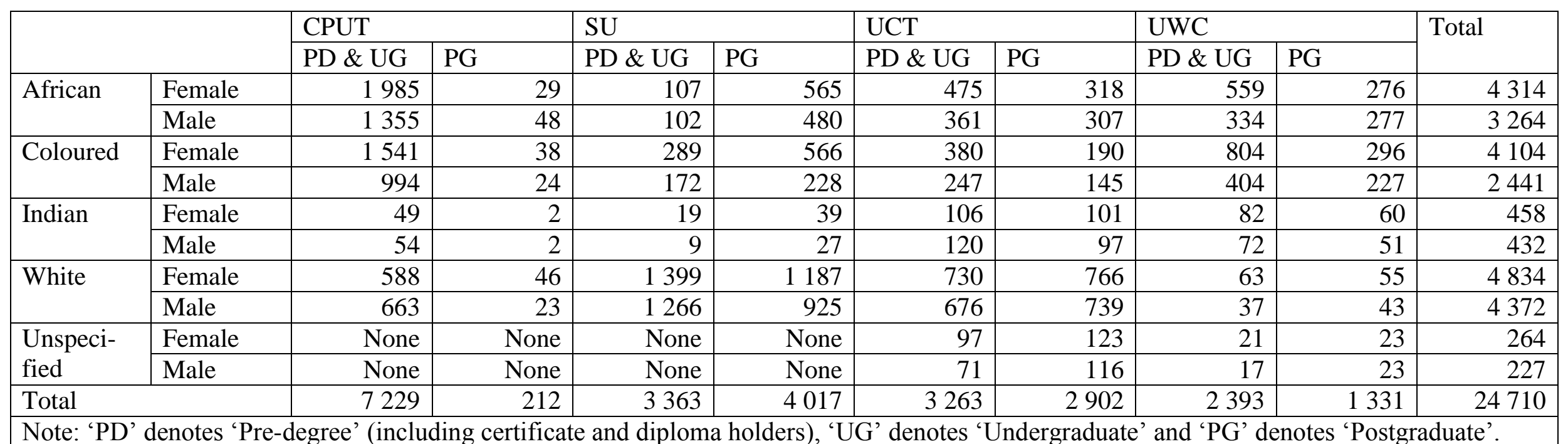

Note: 'PD' denotes 'Pre-degree' (including certificate and diploma holders), 'UG' denotes 'Undergraduate' and 'PG' denotes 'Postgraduate'. 
committee already provided from their respective HEMISs. Instead, the research team approached the National Student Financial Aid Scheme (NSFAS) for any contact details it may have had on record for graduates who may have received NSFAS bursaries. It was assumed that students may have been more proactive in updating their details with the NSFAS as many may have depended on the scheme to repay loans or study further. Using student numbers to match records in the sample frame with records received from the NSFAS, the research team was able to add emails and/or mobile numbers for 3781 graduates across CPUT and UWC - the two universities with the lowest proportions of contactable graduates. Of these graduates, 1268 had no email or mobile number from the HEMIS data, thus increasing the contact range by an additional 1268 graduates across CPUT and UWC, apart from possibly having updated or augmented contact details for 2513 other graduates, at least in terms of emails and mobile numbers.

Upon completion of the sample frame, all graduates at SU and UWC were contactable by email at least, but only by virtue of having obtained student emails from the HEMIS data for all those who had no private email. 'Student emails' are universitygenerated emails all students receive whilst registered for a qualification. Fortunately, student emails were kept active at SU and UWC, but not at CPUT and UCT. Many students studying further may still have been using these emails, while others may have placed forwarding addresses to their private or work email. Assuming all other contact details to have been accurate (which, of course, was unrealistic!), only 622 graduates from CPUT (about $8 \%$ of CPUT's total) were presumably not contactable by email or phone. Of these, 98 graduates had no or incomplete postal details, most of which were foreign citizens. Similarly, only 44 graduates from UCT (less than 1\% of UCT's total) were not contactable by email or phone. Of these, 11 graduates, again, most of which were foreign citizens, had no or incomplete postal details. The compilation of the 
sample frame for the Western Cape survey therefore enabled nearly all 24710 graduates to be contacted either by email, phone or post. Consequently the research team targeted all graduates instead of a sample to maximise response rates and to allow for refusals and inaccurate contact details.

\section{Administering the survey}

At the outset it was decided that the survey was to be administered online only due to a lack of postal details and the population comprising (mostly 'young') graduates. Following a number of iterative workshops with the reference group and education-andtraining experts, the research team designed a questionnaire focussing mainly on graduates' experience of university, finding employment and studying further (see CHEC [2013, 102-111] for a printed version of the online questionnaire). Due to the unique context and focus of the Western Cape graduate destination survey, much of the questionnaire had to be developed from a limited knowledge base apart from standard questionnaire design principles, while the notion of different 'pathways' from study to work had to be carefully conceptualised to accommodate a wide range of occupational scenarios applicable to the South African context.

Once the final version of the questionnaire was approved by a management committee, the call centre programmed an online version of the questionnaire. Sixteen graduates, two undergraduates and two postgraduates from each of the four universities, were randomly selected and asked to pilot the questionnaire in return for a small shopping voucher as reward. Six of these could not be reached or failed to respond and were substituted with different research team members assuming the role of different types of graduates. No major concerns or difficulties were raised during the pilot, while filters around the different pathways from study to work were thoroughly tested. Given that none of the participating graduates raised any serious concerns, there was little 
concern over having substituted the missing six with mock graduates. The survey was officially launched online on Monday the $10^{\text {th }}$ of September 2012 following final linguistic and technical edits to the questionnaire.

A cover letter, signed on behalf of each graduate's respective Vice Chancellor, was emailed to graduates in personalised emails with each graduate's own student number as reference. Although the Australian Course Experience Questionnaire requires students to identify themselves by filling in their student numbers (Harris and James 2010), the research team argued that it would have been unreasonable for graduates to have their student numbers at hand two years after studying, especially postgraduates who are seldom required to use their student numbers. The cover letter introduced the survey, highlighted the importance thereof, and provided instructions for accessing and completing the survey online with a clear web-link. Graduates could only access the survey by logging in with their student numbers that they received by email to ensure legitimacy and tracking of responses. The cover letter also offered incentives for completing the survey through lucky draws in which graduates could win one of several gift vouchers and iPad's, two of which were donated by the South African Graduate Recruiters Association. Unfortunately, the survey coincided with another online commercial survey of graduates across South Africa, while this would have no doubt influenced response rates negatively (e.g., see Porter, Whitcomb and Weitzer [2004] regarding survey fatigue amongst students).

Still, a total of 2359 graduates (9.6\% of the full cohort of 24710 graduates) responded within a week following the launch of the survey, after which the response rate dropped noticeably. Although a 9.6\% response rate was above the norm of $5.6 \%$ for population sizes around 20000 and above (assuming a 99\% confidence level) (Neuman $2011,265)$, the research team was concerned about the extent to which a $9.6 \%$ sample 
was sufficiently representative for (1) a population as diverse as a full cohort of graduates from an entire province (as reflected by the 80 different subgroups in Table 1), (2) lower than average response rates from CPUT and UWC (the two universities accommodating proportionally larger numbers of students from more disadvantaged backgrounds), and (3) subsequent disaggregated analyses for particular subgroups. Consequently the research team asked the call centre to conduct a series of prompting activities to increase response rates. The first included two email reminders late September and early October. The second included phone calls to all graduates who had a valid home number, but no email or mobile number. Of these, 2923 graduates verified their emails and mobile numbers after which they were emailed the cover letter and accompanying web-link. After small increases in response rates, a third activity included posting the cover letter to 1153 graduates with postal addresses, but no email or phone numbers, encouraging them to complete the survey online. Following these activities, only 620 additional responses were received by the end of October - a mere $2.5 \%$ extra of the cohort of 24710 graduates, which is considered a negligible reduction in the percentage sampling error under normal circumstances (Neuman 2011, 265). Also, of the total of 2979 online responses, 106 were invalid as graduates accessed and submitted their questionnaires online without completing any questions. Thus, a total of 2873 valid online responses were finally obtained $-11.6 \%$ of the cohort of 24710 graduates.

However, response rates varied considerably across the four universities, with UCT at $18.1 \%$, SU at $11.9 \%$, UWC at $10 \%$ and CPUT at $6.8 \%$. CPUT's response rate was of particular concern as CPUT had proportionally more certificate and diploma holders, while determining employment levels amongst these graduates was of critical interest due to perceived higher levels of unemployment amongst certificate and 
Table 2. Percentage response rate by race, gender, university and qualification type.

\begin{tabular}{|c|c|c|c|c|c|c|c|c|c|c|}
\hline & & \multicolumn{2}{|l|}{ CPUT } & \multicolumn{2}{|l|}{ SU } & \multicolumn{2}{|l|}{ UCT } & \multicolumn{2}{|l|}{ UWC } & \multirow[t]{2}{*}{ Total } \\
\hline & & PD \& UG & PG & PD \& UG & PG & PD \& UG & PG & PD \& UG & PG & \\
\hline African & Male & 27.3 & 20.8 & 28.4 & 27.1 & 19.4 & 27.0 & 32.3 & 31.0 & 27.1 \\
\hline Coloured & Male & 22.0 & 12.5 & 18.0 & 26.8 & 18.6 & 24.1 & 28.7 & 26.4 & 23.4 \\
\hline \multirow[t]{2}{*}{ Indian } & Female & 22.4 & 0.0 & 31.6 & 23.1 & 18.9 & 24.8 & 26.8 & 21.7 & 23.1 \\
\hline & Male & 18.5 & 0.0 & 11.1 & 25.9 & 15.8 & 20.6 & 15.3 & 13.7 & 17.4 \\
\hline \multirow{2}{*}{$\begin{array}{l}\text { Unspeci- } \\
\text { fied }\end{array}$} & Female & N/A & N/A & N/A & N/A & 20.6 & 18.7 & 19.0 & 4.3 & 18.2 \\
\hline & Male & N/A & N/A & N/A & N/A & 25.4 & 29.3 & 35.3 & 34.8 & 29.1 \\
\hline \multicolumn{2}{|l|}{ Total } & 22.2 & 9.4 & 20.0 & 22.9 & 20.8 & 23.1 & 26.7 & 26.7 & 22.5 \\
\hline
\end{tabular}


diploma holders. Consequently the research team decided that the call centre should conduct the questionnaire telephonically with graduates who had not yet responded to increase response rates even further. Call centre operators were to read questions and answer options to graduates and capture their responses directly into the survey dataset. The call centre started calling non-responding graduates from randomly sorted lists per university until a total response rate (online and telephonic responses included) of at least $21.5 \%$ were obtained for each university - the maximum rate given time and budgetary constraints. Finally, 2687 telephonic responses were obtained, yielding a final total, together with the 2873 online responses, of 5560 responses $-22.5 \%$ of the cohort of 24710 graduates, with UWC now at $26.7 \%$, UCT at $21.9 \%$, CPUT at $21.8 \%$ and SU at $21.6 \%$. Table 2 shows percentage response rates for each of the 80 subgroups as per the original sample frame.

Each of the 80 subgroups in Table 2, except three, yielded responses. Postgraduate white males from UWC yielded the highest rate (32.6\%) while postgraduate white females from CPUT yielded the lowest (6.5\%), although both these groups had low population numbers to start with (43 and 46 respectively). There were no responses from postgraduate Coloured and Indian females and Indian males from CPUT, although, again, there were only two Indian females and males in these respective subgroups. To compensate for the variation in response rates between subgroups, even though the variation was reasonably contained, statistical weights were calculated for each subgroup by dividing the population of a particular subgroup by the number of responses received in that subgroup. Weighing the data to reflect the actual population of 24710 graduates along these subgroups allowed for more accurate inferences around race, gender, university, and qualification type. Moreover, decisionmakers were interested in knowing estimated real numbers of graduates that were 
employed, unemployed, studying further, etc. Because of the relative sociodemographic similarity between postgraduate Coloured males from CPUT, and the 'missing' postgraduate Coloured and Indian females and Indian males from CPUT, responses from postgraduate Coloured males from CPUT were weighted to account for these three missing subgroups as well (see Table 2).

Upon completion of the survey, the call centre emailed a letter of thanks signed by the CEO of CHEC to all graduates who participated in the survey. The letter also included a web-link through which graduates could access the survey report. In addition, graduates were informed that the survey may be repeated in four years' time and kindly requested to update their emails with their respective alumni offices using an email provided for each alumni office.

\section{Comparing online and telephonic responses}

Prior to analysing the data, there was a concern that telephonic responses may have been less valid than online responses due to survey fatigue resulting from administering a lengthy and complex questionnaire telephonically. For example, categorical questions with numerous answer options could have caused a response pattern biased towards earlier options in an attempt to 'get on with it'. Tiring call operators could easily have mispronounced or omit words or even whole phrases altogether. Some questions would also have required graduates to reflect more carefully on the range of options before answering, which would have been more difficult to do with an operator reading out options one-by-one. To determine whether there were response effects between online and telephonic responses, results were compared for two questions in two scenarios.

The first question was about employment status, which was the most important question in the study. The second question was about different means of finding employment, which included the most items of all questions in the questionnaire (18 in 
total) and that would have been the most difficult to conduct telephonically. If no substantial differences existed between online and telephonic responses, it could be safely assumed that fatigue or response pattern bias did not impact negatively on the overall results of the study.

Cross-tabulations of these two questions by survey mode (i.e., online versus telephonic) were evaluated to determine influence of survey mode on responses. Pearson's chi-square was used to test the null hypothesis of no association between survey mode and the categories of the two questions. However, chi-square is known for its sensitivity to large samples, thereby yielding inflated values indicating statistically significant results which may not necessarily be meaningful and of little practical importance. The phi coefficient was therefore also calculated as a measure of effect size to quantify the magnitude of the interaction or dissimilarity in responses between the two survey modes.

The analyses were performed for two scenarios; firstly for all four universities combined and secondly for SU only, since SU came closest to a 50/50 distribution between online and telephonic responses. Table 3 shows the results of these analyses.

Table 3. Statistical results of online versus telephonic responses.

\begin{tabular}{|l|l|}
\hline \multicolumn{1}{|c|}{ All four universities combined } & \multicolumn{1}{c|}{ SU only } \\
\hline $\begin{array}{l}\text { What was your employment status on } 1^{\text {st }} \text { of September 2012? (Most important } \\
\text { question in the study (7 items)) }\end{array}$ \\
\hline$\chi^{2}(6)=117.086 ; \mathrm{p}<0.001 ; \mathrm{n}=5499$ & $\chi^{2}(6)=20.991 ; \mathrm{p}=0.002 ; \mathrm{n}=1575$ \\
\hline Phi $=0.146$ & Phi $=0.115$ \\
\hline $\begin{array}{l}\text { What was the primary method of finding the job you had on } 1 \text { st of September 2012? } \\
\text { (Question with most items }(18 \text { items) })\end{array}$ \\
\hline$\chi^{2}(17)=167.392 ; \mathrm{p}<0.001 ; \mathrm{n}=3701$ & $\chi^{2}(17)=84.450 ; \mathrm{p}<0.001 ; \mathrm{n}=1040$ \\
\hline Phi $=0.213$ & $\mathrm{Phi}=0.285$ \\
\hline
\end{tabular}

As expected, the chi-squares are all significant at the $95 \%$ confidence level due to the large samples. The phi coefficients, however, signify that these results are of little 
practical importance irrespective of the question or scenario being considered.

Coefficients range from 0.115 to 0.285 , indicating small to lower-than-medium effect sizes (Cohen 1988). In addition to the information in Table 3, only a few of the cell standardized residuals were significant, thus confirming that the differences between observed and expected counts were insubstantial. The few items that did in fact yield significant standardised residuals (i.e., significant differences between online and telephonic responses) could be explained though by making reasonable assumptions about the type of graduate likely to have responded online or telephonically. For example, in the question on employment and in the scenario considering all four universities, a larger proportion of online respondents were studying further as opposed to telephonic respondents (with standardised residuals of 3.2 and -3.3 respectively), which could be ascribed to universities most likely having more up-to-date email addresses for graduates studying further, hence, causing them to respond online.

Still, such differences should not be ignored completely while the inclusion of certain items in telephonic surveys should be carefully considered as fatigue or response pattern bias remains a possibility. Nevertheless, since the split in survey mode did not impact negatively on the overall results of the study, online and telephonic responses were analysed as a single sample.

\section{Conclusion}

The purpose of this article was to describe the methodology of the Western Cape graduate destination survey, particularly the compilation of a sample frame with reliable contact details and administering a survey mode to yield maximum response rates. In addition, the difference in responses between online and telephonic surveys was discussed. Although the literature discusses many strategies to improve response rates to online surveys (e.g., see Porter [2004b], Nair, Adams and Mertova [2008], Nulty 
[2008], and Bennett and Nair [2010], as well as Alderman, Towers and Bannah [2012, 272] for additional references), such strategies pertain mostly to student evaluation surveys conducted shortly before, during or immediately after graduation, while graduate destination surveys pose the difficulty of tracing students several years after graduation. The purpose here is therefore not to repeat a discussion of strategies already known to improve response rates, but to conclude with three methodological suggestions that add to the literature on student surveys in general and graduate destination surveys in particular. The article concludes by highlighting some of the benefits of the Western Cape graduate destination survey.

Firstly, graduate destination surveys depend foremost on a sample frame with reliable contact details, especially emails and mobile numbers, while postal details might even be insignificant in future. While there are many strategies to improve response rates, most are of no use if graduates cannot be reached. Compiling the sample frame for the Western Cape survey proved the value of universities keeping proper records of student contact details, and the difficulty when such details are not recorded properly. If universities wish to reach graduates in an increasingly digitalised era, be it for alumni or survey purposes, then they need to implement more reliable ways of verifying and updating details, especially private emails and mobile numbers, prior to students exiting their systems upon graduation. With the use of graduate destination surveys to track issues such as graduate employment in a globalising market economy, especially against the backdrop of responsiveness and performance ratings in higher education, such verification may be imperative. The question though is how best to verify and update contact details, while this also depends on how each university manages its records. In addition to universities needing to keep proper records, researchers need to allow sufficient time for standardising databases from different 
universities (for regional or national graduate destination surveys) and follow-up other possible sources of contact details to improve the contact range and subsequent response rates, as was the case with the NSFAS in the Western Cape survey. In hindsight, the call centre could have contacted all graduates with mobile or home numbers prior to launching the survey online to verify private emails. Such a pre-survey phase could then also have been used to make graduates aware of the upcoming survey and its importance - a strategy Bennett and Nair $(2010,362)$ argue improves response rates, provided though that additional costs can be covered.

Secondly, the bulk of graduates who will respond to an online graduate destination survey will probably do so within about a week of receiving the survey, after which responses drop noticeably. Although several authors mention the role of reminders to improve response rates (Porter 2004b, 11; Nair, Adams and Mertova 2008, 230-231; Nulty 2008, 303; Bennett and Nair 2010, 362), reminders in the Western Cape survey appeared to have had a marginal effect on response rates. However, much depends on how, when and how many reminders are sent, and of course the accuracy of contact details. Lack of information made it difficult for the research team to determine the actual effect of reminders, e.g., one simply could not be sure which graduates responded to reminders and which responded to the original cover letters. Also, reminder emails were simply sent to all non-respondents with emails, yet, the extent to which these emails actually reached graduates is unknown. Still, reminder emails may as well be sent due to their low costs and automated procedures, since marginal improvements in response rates are better than no improvements at all. A proper costbenefit analysis should be conducted though if reminders involve more expensive means such as postcards or phone calls. 
Thirdly, although graduate destination surveys are usually administered online, they can, if necessary, also be administered telephonically should concerns arise over responses rates from certain subgroups. Despite the difference between the two survey modes and the effect this may have on the validity of responses, in the Western Cape survey it was found that the split in survey mode did not impact negatively on the overall results of the study, while online and telephonic responses can be analysed as a single sample. However, the possibility remains that certain question items may yield inexplicable differences in responses, while resources should ideally be utilised to maximise online responses instead of augmenting them with telephonic surveys. Still, given the usefulness of employing call centres to manage certain aspects of graduate destination surveys, such as keeping graduates informed throughout the course of a survey, further research on the merit of online versus telephonic surveys is necessary.

Following the release of the CHEC report the Western Cape graduate destination survey has been received favourably whilst providing important information on Western Cape graduate employment. For example, the far majority of graduates (84\%) were employed part- or fulltime in the public or private sectors two years after graduation, while unemployment stood at $10.1 \%$. Self-employment and informal sector employment were negligible (3\% and $0.9 \%$ respectively), while only $1.9 \%$ of graduates were unemployed, but not looking for work (CHEC 2013, 41). Following the Western Cape survey, a proposal was written by the national association of Vice Chancellors (Higher Education South Africa (HESA)), to undertake a national graduate destination survey across all 23 universities in South Africa. The HESA proposal highlighted the following potential benefits of graduate destination surveys against the backdrop of the Western Cape survey. These included; (1) understanding pathways from study to work, (2) profiling graduates at risk of unemployment, (3) improving curriculum development, 
(4) improving the impact of career advice offices and work-placement services, and (5) improving institutional data management.

\section{References}

Alderman, L., S. Towers, and S. Bannah. 2012. "Student feedback systems in higher education: a focussed literature review and environmental scan." Quality in Higher Education 18 (3): 261-280.

Ardalan, A., R. Ardalan, S. Coppage, and W. Crouch. 2007. “A comparison of student feedback obtained through paper-based and web-based surveys of faculty teaching." British Journal of Educational Technology 38 (6): 1085-1101.

Bennett, L., and C. S. Nair. 2010. "A recipe for effective participation rates for webbased surveys." Assessment \& Evaluation in Higher Education 35 (4): 357-365.

Cape Higher Education Consortium. 2013. Pathways from university to work: A graduate destination survey of the 2010 cohort of graduates from the Western Cape Universities. Wynberg: Cape Higher Education Consortium.

Cohen, J. 1988. Statistical power analysis for the behavioral sciences. Hillsdale, NJ: Lawrence Erlbaum.

Development Policy Research Unit. 2006. Graduate unemployment in post-apartheid South Africa: Nature and possible policy responses. Research compiled for Standard Back and Business Leadership South Africa. School of Economics, University of Cape Town.

Dommeyer, C. J., P. Baum, R. W. Hanna, and K. S. Chapman. 2004. "Gathering faculty teaching evaluations by in-class and online surveys: their effects on response rates and evaluations." Assessment \& Evaluation in Higher Education 29 (5): 611-623.

Harris, K-L. and R. James. 2010. The Course Experience Questionnaire: Graduate Destination Survey, and Learning and Teaching Performance Fund in Australia. Public Policy for Academic Quality. Higher Education Dynamics 30: 99-119.

Letseka, M., M. Cosser, M. Brier, and M. Visser. 2010. Student retention and graduate destination: Higher education and labour market access. Pretoria: Human Sciences Research Council.

Magnet. 2008. "Magnet Professionals' Survey 2008”. Magnet Communications. Accessed 4 October 2013. 
http://www.fpi.co.za/Portals/5/docs/2008\%20Report\%20Magnet\%20Young\%20 Professionals\%20Survey.pdf

Mugabushaka, A-M., U. Teichler, and H. Schomburg. 2003. "Failed or self-hindering prophecies? Employment experiences of African graduates in the 1990s." Journal of Higher Education in Africa 1 (1): 57-77.

Nair, C. S., P. Adams, and P. Mertova. 2008. "Student engagement: The key to improving response rates." Quality in Higher Education 14 (3): 225-232.

Neuman, W. L. 2011. Social research methods: Qualitative and quantitative approaches. Boston: Pearson.

Nulty, D. D. 2008. "The adequacy of response rates to online and paper surveys: what can be done?" Assessment \& Evaluation in Higher Education 33 (3): 301-314.

Porter, S. R. 2004a. "Pros and cons of paper and electronic surveys." New Directions for Institutional Research 121: 91-97.

Porter, S. R. 2004b. “Raising response rates: What works?” New Directions for Institutional Research 121: 5-21.

Porter, S. R., M. E. Whitcomb, and W. H. Weitzer. 2004. "Multiple surveys of students and survey fatigue." New Directions for Institutional Research 121: 63-73.

Schomburg, H., and U. Teichler. 2006. Higher education and graduate employment in Europe: Results from graduate surveys from twelve countries. Higher Education Dynamics 15. Dordrecht: Springer.

Smith, K., and T. Bers. 1987. "Improving alumni survey response rates: An experiment and cost-benefit analysis." Research in Higher Education 27 (3): 218-225.

Teichler, U. 2002. "Graduate employment and work in Europe: Diverse situations and common perceptions." Tertiary Education and Management 8: 199-216.

Universum. 2013. “Universum Professional Survey 2012/2013”. Universum Communications. Accessed 4 October 2013. http://www.fpi.co.za/Portals/30/docs/survey/SAPS\%202012_2013\%20Partner\% 20Report\%20-\%20FPI.pdf

Van der Berg, S., and H. Van Broekhuizen. 2012. Graduate unemployment in South Africa: A much exaggerated problem. Stellenbosch Economic Working Papers 22/12. A working paper of the Department of Economics and the Bureau for Economic Research at the University of Stellenbosch. 